\title{
(6) Adapting oil and gas drilling techniques for the mining industry with dewatering well placement technology
}

\author{
by A. Rowland*, M. Bester ${ }^{\dagger}$, M. Boland ${ }^{\ddagger}$, C. Cintolesi§, and \\ J. Dowling**
}

\section{Synopsis}

Although increasing R\&D spent to develop original technologies will benefit the mining industry, adaptation of appropriate existing technologies from other industries can be a more cost-effective alternative. Schlumberger Water Services, now WSPIParsons Brinckerhoff, has undertaken a 6-year programme assessing the adaptation of oil and gas $(O \& G)$ drilling and geophysical characterization techniques to a range of mining applications, including dewatering. Conventional dewatering systems for open pit mines generally use vertical boreholes that target hydraulically productive zones within an orebody. The drilling and completion of vertical dewatering boreholes can be complicated by mine planning constraints, where optimum hydrogeological targets are not accessible from the available drilling locations. As these boreholes are often located within the operating open pit, they can interfere with the mining operation and the ability to carry out significant dewatering ahead of mining is limited. Dewatering Well Placement Technology (DWPt) is WSP|Parsons Brinckerhoff's next-generation mine dewatering solution aimed at addressing the limitations of conventional dewatering systems through placement of permanent, high-performance dewatering wells in optimum orientations beneath an open pit using largediameter directional drilling technology commonly used in O\&G. Ideally, well collars are located outside of the mine operating areas, resulting in improved compatibility between the dewatering system and mine plan. Recently drilled and constructed pilot directional dewatering wells in hard rock mining environment in the USA and Mexico have demonstrated that DWPt offers significant benefits for groundwater inflow control and value to mining operations compared to conventional open pit mining dewatering practices.

Keywords

open pit mines, dewatering, well placement, directional drilling.
> Wet drilling and blasting, requiring more expensive blasting agents and reduced fragmentation efficiency

> Wet working benches, which increase equipment wear and introduces additional safety risk factors

> Inundation of the pit floor and slow mine advancement

> Reduced geomechanical performance of pit slopes that, in some cases, leads to the design of more conservative slope angles resulting in higher strip ratios and deferral or loss of ore (Figure 1).

Although conditions vary widely, where wall stability and reducing groundwater inflow are the main dewatering objectives, conventional dewatering is normally implemented with a combination of: (1) in-pit vertical pumping wells to remove groundwater from the formation and lower groundwater levels within the ultimate pit shell, (2) pit perimeter wells to intercept and remove groundwater moving toward the mine, and (3) a series of sumps and surface pumps to remove standing and near surface groundwater (Dowling and Rhys-Evans, 2015) (Figure 2). This tends to be effective for ore deposits in moderate to high permeability settings where productive zones are present and within the reach of conventional drilling techniques.

\section{Adapting innovation}

The petroleum industry has faced many of the same challenges as those currently facing the mining industry, especially in terms of declining grades and a precipitous decrease in large, easily accessible discoveries (McCartney and Anderson, 2015). However, in order to address this, the O\&G industry has maintained significant investment in research and development $(R \& D)$ (McCartney and

Piteau Associates, South Africa.

† Kumba Iron Ore, South Africa.

\# WSP | Parsons Brinckerhoff, United Kingdom.

$\S$ Anglo American, Chile.

** Piteau Associates, USA.

(C) The Southern African Institute of Mining and Metallurgy, 2017. ISSN 2225-6253. This paper was first presented at the New technology and innovation in the Minerals Industry

Colloquium', 9-10 June 2016, Emperors Palace, Johannesburg, South Africa. 


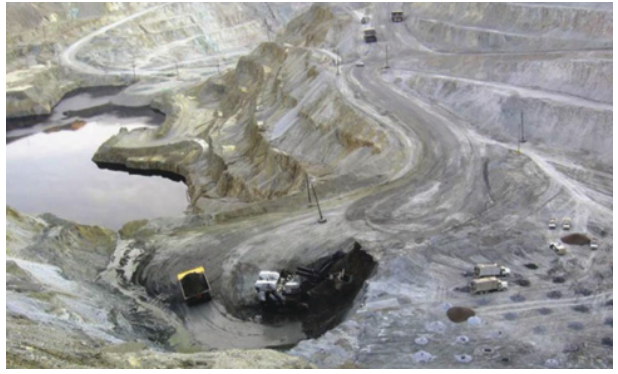

Figure 1-Many large open pit operations are eventually impacted by the inflow of groundwater, requiring proactive dewatering systems

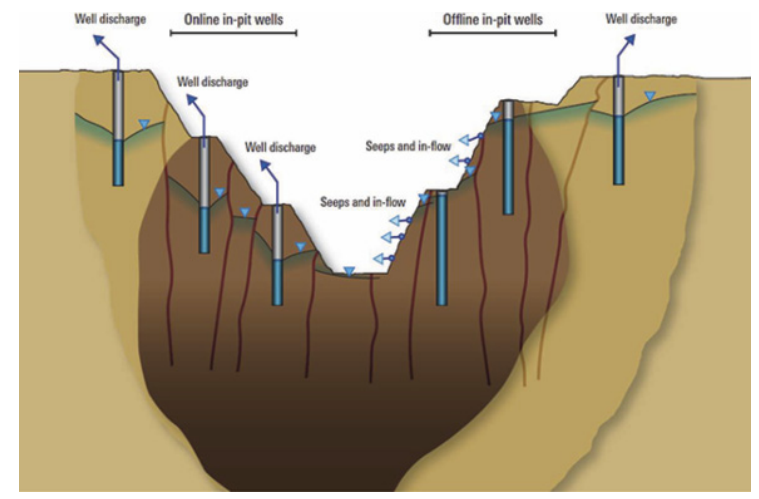

Figure 2-A conceptual layout of a conventional dewatering system in a hard rock, fractured environment. Some or all of the various aspects illustrated may be included in any given system, and often a combination is deployed based on local requirements (Dowling and Rhys-Evans, 2015)

Anderson, 2015). R\&D spend as a percentage of revenue averages around $0.5 \%$ for the major oil companies, and is higher than $2 \%$ for the main service companies (McCartney and Anderson, 2015). In contrast, R\&D spend in the mining industry has previously been pegged in the media at as little as one-tenth of that in the $O \& G$ industry.

Directional drilling as a whole is considered a mature technology with widespread acceptance and commonplace use in the $0 \& G$, utilities, and infrastructure industries. However, directional well placement in hard rock mining has a very limited track record and was previously untested for dewatering applications in an open pit mine. The geological and geomechanical environments, size and scale of equipment, flow and production pumping regime, and the associated well design requirements are significantly different, requiring substantial adaptation and modification. However, WSPIParsons Brinckerhoff and Freeport-McMoRan recognized that the principal benefits of directionally drilled dewatering wells are highly applicable to open pit mine dewatering (Dowling and Rhys-Evans, 2015). Crucially, the use of directional drilling enables:

> Enhancement of hydraulic contact between multiple fractures zones and the production well or wells

> Access to permeable water-bearing zones unreachable with vertical drilling

> Positioning of the well-heads permanently outside of the planned mine operating areas.

The combined impact of the benefits listed above has been shown to result in a step-change improvement in dewatering well efficiency, performance, and overall effectiveness of the mine dewatering programme, resulting in significant cost and risk reductions. Improvements that have been demonstrated by pilot programmes in the USA and Mexico are:

> Increased well yield due to the design trajectory, interception of sub-vertical structure, and enhanced hydraulic contact.

- Improved well runtimes with the well-heads located outside of operating areas, thereby avoiding interference between dewatering infrastructure and mine operations

> High well yield and improved runtimes leading to a step-change increase in long-term volumes of groundwater produced from the dewatering programme

> Reduced number of well-head installations with associated burdens of procurement, implementation, and in-pit operation interactions.

Recognizing the limitations of conventional dewatering practices and the potential value of improved dewatering, WSPIParsons Brinckerhoff and Freeport-McMoRan have collaborated to develop, test, and implement a new generation of high-performance mine dewatering well systems, combining mine hydrogeology and dewatering expertise with crossover technology of $O \& G$ directional well placement (Dowling and Rhys-Evans, 2015) (Figure 3). Subsequently, the success of various pilot programmes at Morenci with Freeport McMoRan led Kumba Iron Ore (KIO) to approach WSPIParsons Brinckerhoff to conduct a technical feasibility study (TFS) for the evaluation of directional well placement to improve dewatering effectiveness at their Sishen operation in South Africa.

Adaptation of existing technology requires a deep understanding of the goals of the adaptation, as well as the technology to be adapted. For example, the directional placement of a well to a pre-planned trajectory involves complex interactive consideration of multiple factors, including the ore deposit geology, geological structure and geomechanical environment, the ranges of performance for directional tools, downhole surveying, and the ability to control and steer the well to the target (Dowling and RhysEvans, 2015). The trade-offs between alternative options, risk factors, the final dewatering goal, and overall value to the mine operation are integral to the matrix of planning, design, and implementation decisions. By adapting these techniques from the $O \& G$ industry, WSPIParsons Brinckerhoff and Freeport-McMoRan developed a mine dewatering project integration matrix, which was subsequently implemented at the Freeport-McMoRan Morenci copper mine in Arizona, with the previously mentioned TFS having been done for KIO's Sishen operation.

\section{Proof of concept}

To date, two directionally placed dewatering wells have been successfully implemented at Morenci as part of the Garfield open pit mine dewatering programme. An initial well was constructed on a 'proof-of-concept' basis and commissioned in early April 2013. The well site was located on the west wall of the open pit, outside of planned mining limits. The borehole was steered underneath the centre of the planned pit on a pre-planned directional trajectory. Attaining a measured depth of approximately $700 \mathrm{~m}$, the well intercepted hydrogeological targets associated with major northeast-trending geological structures and hydrogeological compartments. After completion, the well was equipped with an oilfield-style high-lift, slim-hole electrical submersible pump system designed to minimize well drilling and construction hole diameters while permitting high production pumping rates for variable head pressure conditions (Figure 4). The well initially produced between $150 \mathrm{~m}^{3} / \mathrm{h}$ and $160 \mathrm{~m}^{3} / \mathrm{h}$, which 


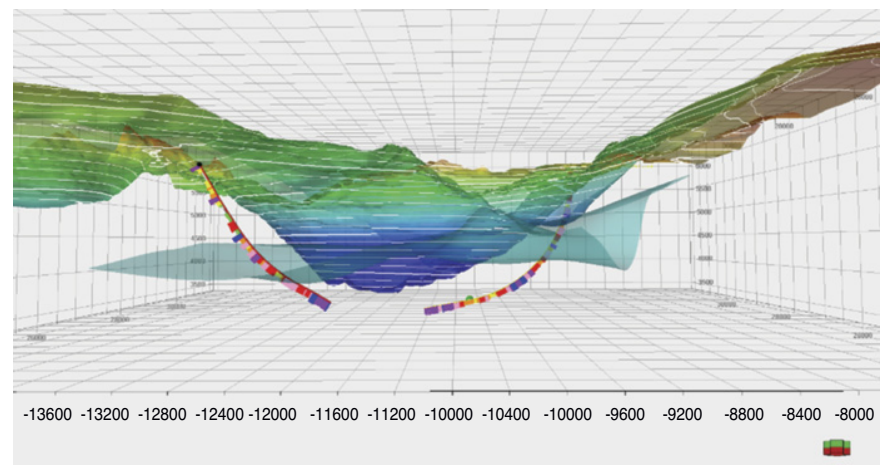

Figure 3-3D visualizations of directional well placement trajectories beneath the Garfield pit at the FreePort McMoRan Morenci Copper Mine, USA with January 2014 phreatic surface shown. The trajectory on the left (Well C) is the proof-of-concept well completed in April 2013, while the trajectory on the right (Mammoth Well) was completed in January 2015. The cross-section runs from NNW to SSE (Dowling and Rhys-Evans, 2015)

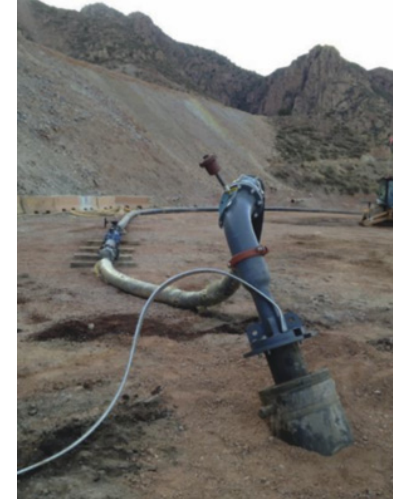

Figure 4-The collar of the first directionally placed well at Morenci, permanently plumbed and operating outside the footprint of the Garfield Pit

was at the high end of the planned production, and is five to ten times greater than the previously installed conventional, vertical in-pit wells. The well was immediately commissioned into the active dewatering programme and during the first year operated at $96 \%$ availability. Due to the combination of high production rate and high availability, it effectively produced up to two orders of magnitude more groundwater than any of the pre-existing in-pit vertical wells and exceeded the combined groundwater production from the rest of the dewatering system, comprised of six vertical production wells (Dowling and Rhys-Evans, 2015).

Following the success of the first well at Morenci and another successful well in Mexico, Freeport-McMoRan in partnership with WSPIParsons Brinckerhoff commissioned an additional programme to construct a second well collared on the pit perimeter of the east high wall. The target for the second well was a set of northeast-trending geological structures and lower permeability compartments. With a more aggressive drill bit trajectory, design modifications were made during implementation to control risk while attaining the planned hydrogeological target. Results from early stages of operation indicate the well to be a high-performance highvalue dewatering asset (Dowling and Rhys-Evans, 2015).

Since initiation of the programme at Morenci, monitoring data has shown a distinct acceleration in the rate of the groundwater level reduction in the open pit. A number of piezometers located within and around the edges of the pit have shown a $200-250$ foot $(60-90 \mathrm{~m})$ decline in static water elevation (Dowling and Rhys-Evans, 2015).

\section{South African example}

The Sishen iron ore mine, Kumba Iron Ore's flagship operation, is currently the largest open pit iron ore mine in Africa, and one of the largest open pits mines in the world at almost $14 \mathrm{~km}$ in length (Kumba Iron Ore, 2016a). Total annual production at Sishen is approximately $35 \mathrm{Mt}$, with the most recent values being $5842 \mathrm{kt}$ in the first quarter of 2016 (Kumba Iron Ore, 2016a). Additionally, up to $190 \mathrm{Mt}$ of waste is removed annually from the open pits (Kumba Iron Ore, 2016b). This large-scale mining operation targets a high-grade haematite orebody with grades of significantly more than $60 \% \mathrm{Fe}$ and a sought-after lump content that commands higher prices on the global steel market (Astrup, Hammerbeck, and van den Berg, 1998).

Sishen currently consists of four operating areas that have been excavated to near or below the natural groundwater surface (Schlumberger Water Services, 2014). As a result of the relatively shallow pre-mining groundwater level, dewatering activities have been ongoing since the beginning of mining operations, with a series of vertical inpit and perimeter pumping wells targeting productive geological formations within the mine area (Schlumberger Water Services, 2014). The groundwater regime and rate of mining require that dewatering pumping operates on a continuous basis. The abstraction rate of the overall mine dewatering system is approximately $1800 \mathrm{~m}^{3} / \mathrm{h}$ as of November 2015, from a total installed capacity of approximately $2130 \mathrm{~m}^{3} / \mathrm{h}$ (Nel and White, 2015). Of the four operating pits, the GR35 pit is currently the deepest and is mining at $950 \mathrm{~m}$ above sea level (masl) from an original surface elevation of approximately 1200 masl.

Leading up to early 2014, dewatering operations at GR35 pit faced significant challenges related to lithology, structure, and operations, including:

> Typically 2 to 4 'dry' wells are drilled before a highyielding water strike is intersected at the required depth

> The drill rigs at site could not drill beyond water strikes of $250 \mathrm{~m}^{3} / \mathrm{h}$. Dewatering boreholes were therefore constructed below target abstraction as a result of their limited depth of penetration

> Due to highly fractured formations, exploration boreholes are not reamed and production wells are drilled a few metres away. During production drilling the risk of missing the water-bearing structure encountered in the exploration well close by is significant due to the vertical orientation of structures

> The presence within the pit of dewatering, exploration, and production boreholes and the associated 
dewatering infrastructure interferes with the active mining front and pit operations

> Interruptions to dewatering operations from mining activities resulted in significantly reduced utilization of the production boreholes and a consequent quick rebound of the groundwater system due to high connectivity and hydraulic conductivity.

In order to address the challenges raised above, WSPIParsons Brinckerhoff was approached to conduct a prefeasibility study (PFS), and subsequently a full technical feasibility study (TFS) on the use of directional well placement to replace or augment the existing system in GR35 pit. The PFS concluded that directional wells placed outside of the final pit shell, targeting chert $(\mathrm{CH})$, banded iron formation (BIF), and sub-vertical structures would intercept fracturing that would yield significant amounts of groundwater and lead to effective dewatering of the $\mathrm{CH}, \mathrm{BIF}$, and haematite (HEM) rock mass. Based on this and considering pumping systems, drilling, and completion diameter, a yield of about $360 \mathrm{~m} 3 / \mathrm{h}$ from a single directionally placed well was determined to be an achievable abstraction target (Schlumberger Water Services, 2014). The collar location for the drill pad was proposed by Sishen based on the following criteria (Figure 5):

$>$ Location outside the planned final GR35 pit shell

- Easy access for the drill rig and ancillary services

> Outside areas identified for construction of future waste dumps and therefore the pad could be used for future directional wells if required.

During the TFS, 14 different directional well configurations were assessed, with the Plan 11 and Plan 14 trajectories selected for detailed engineering design and costing. Detailed engineering design work was carried out in order to define the feasibility of drilling the Plan 11 and Plan 14 wells using engineering inputs from a number of groups within Schlumberger, including:

> Smith Bits: drill-bit selection, rate of penetration (ROP) calculations

> Drilling and Measurements: directional drilling plan, bottom hole assembly (BHA) and casing design

> MI Swaco: drilling fluid plan for hole cleaning

> Drilling Tools and Remedial: turbine and mud-motor selection

> Artificial Lift: submersible pump design.

Plan 11 provided a base case as it involved assessment of drilling of all of the main lithologies present at GR35, at a range of drilling diameters from 24 inches to $8 \frac{1}{2}$ inches, with a significant directional component, and completion of a long horizontal production zone within the well that would involve significant challenges and risks. Apart from assessing the technical feasibility of drilling the well, this proposed trajectory also allowed the cost implications of focusing the drilling on the dolomite units, as opposed to the shallower chert and BIF, to be assessed. On the other hand, Plan 14 (Figure 6) presented a simpler well trajectory, which would require less directional drilling to achieve its target placement beneath the GR35 pit. This was assessed to have a higher probability of success, especially considering that this would be the world's first directionally placed dewatering well drilled in iron ore formations. This plan allowed the lower risk associated with the directional drilling component to be assessed against the cost and risk implications of drilling predominantly within the harder and more fractured chert and BIF units. Eventually, the Plan 14 trajectory was selected as the preferred option

A cost-benefit analysis was carried out to compare the current approach to dewatering at Sishen, based on the use of vertical in-pit wells, and the cost associated with developing a dewatering programme based on DWPt. In addition, a number of intangible benefits associated with the DWPt approach were identified, and although the cost benefits of these were not assessed their value was to be considered in assessing the DWPt approach. These intangible benefits, which are applicable for other Sishen open pits and nearby mines (Kolomela), included:

> Improved in-pit safety environment due to reduced personnel movements in the pit related to dewatering activities, and reduced in-pit infrastructure associated with dewatering

> Simplified mine planning due to removal of the need to incorporate dewatering infrastructure and maintenance in-pit

> Improved dewatering leading to:

- More efficient and cheaper blasting. The reduced block size resulting from more effective blasting will in turn reduce the need for crushing, grinding, and potentially drying of material and double-hauling

- Reduced mining equipment maintenance due to lower humidity and acid rock drainage (ARD) generation at the mining front

- Improved ore transportation efficiency due to the reduction in the volume of water carried in ore

- Dewatering infrastructure that will remain in use after backfilling of the GR35 pit, thus supporting ongoing site-wide dewatering supporting GR80 pit.

Overall, multiple conventional vertical well dewatering scenarios were evaluated against the chosen DWP plan. The values for lost revenue were calculated on the basis that benches that could not be mined as a result of high groundwater levels and/or changes to the mine plan as a result of insufficient dewatering would be 'lost'. The value of ore contained in the various benches as per the mine plan would as a result be defined as 'lost revenue'. These were described as follows:

> Scenario 1: 'Most Likely' - conventional dewatering continues as planned and two benches in the base of the pit are lost

> Scenario 2: 'Least Likely' - a best-case scenario where conventional dewatering continues as planned and no benches are lost

- Scenario 3: 'Worst Case' - a worst-case scenario where conventional dewatering continues as planned but four levels in the base of the pit are lost

> Scenario 3: 'DWP' - the planned DWP is executed successfully and all levels in the pit are mined.

The results of the trade-off analysis indicated that although the estimated capex for continued vertical well dewatering was less than that of the proposed DWPt plan, the cost differential was offset by the estimated cost saving related to more efficient dewatering, and the resulting reduction in wet mining and water haulage. Additionally, in the event that the GR35 mine plan could not be met as a result of constraints related to the conventional dewatering system (such as evaluated in Scenarios 1 and 3), high-grade ore representing up to US $\$ 80$ million in revenue could have been lost. Figure 7 shows the relative costs calculated for the various scenarios, clearly indicating that the greatest economic risk lies with potential lost revenue associated with lost benches as a result of the inadequacy of the conventional dewatering system. The lost revenue values used in the costbenefit analysis were calculated at iron ore prices of US\$50 to US\$56 per ton, depending on the accessible volumes of fine and lump ore remaining for each bench in the GR35 pit according to the mine plan at the time. 


\section{Adapting oil and gas drilling techniques for the mining industry}

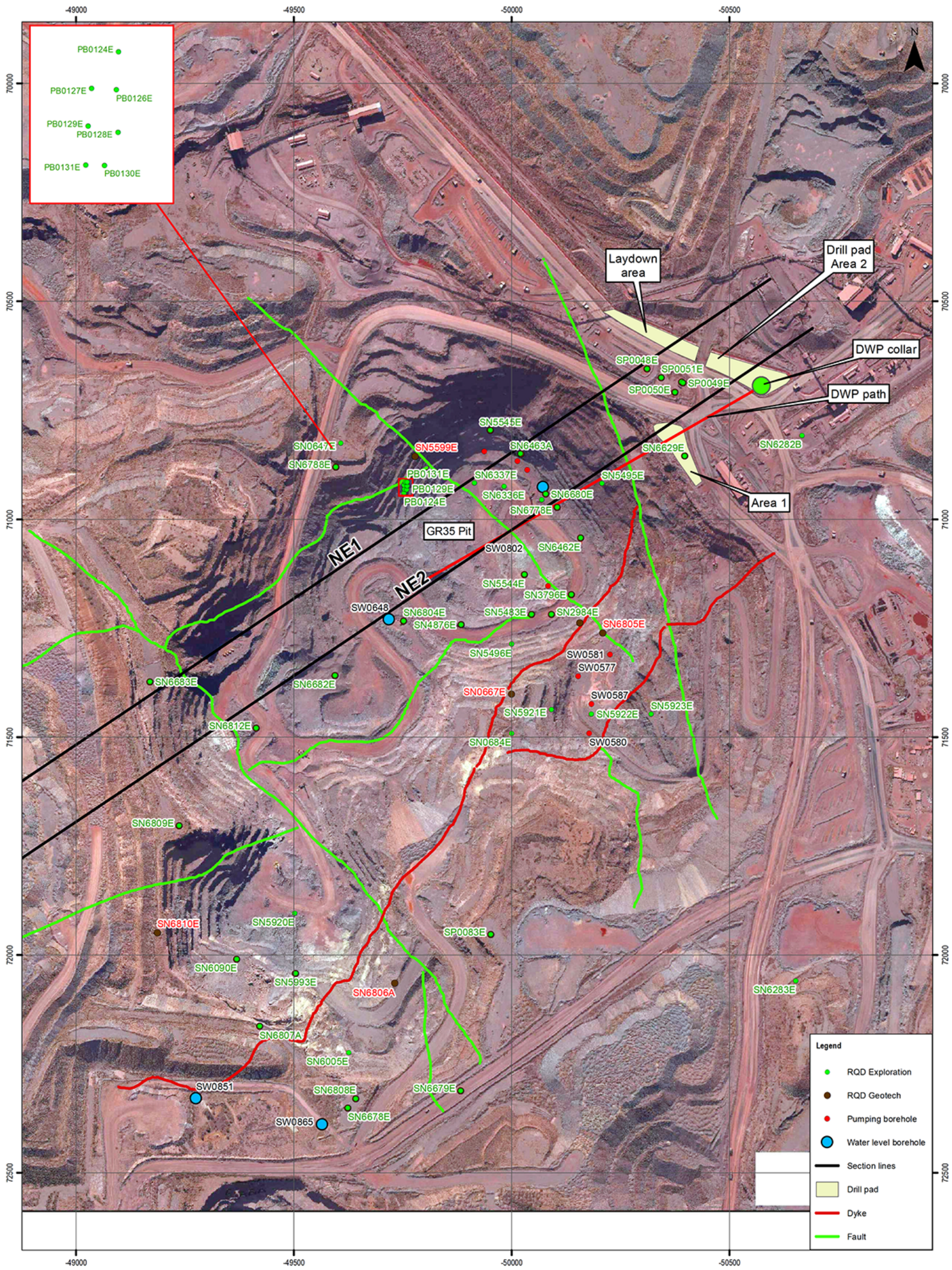

Figure 5-GR35 pit with the location of the DWP collar and drill path shown relative to critical structures and surface infrastructure 


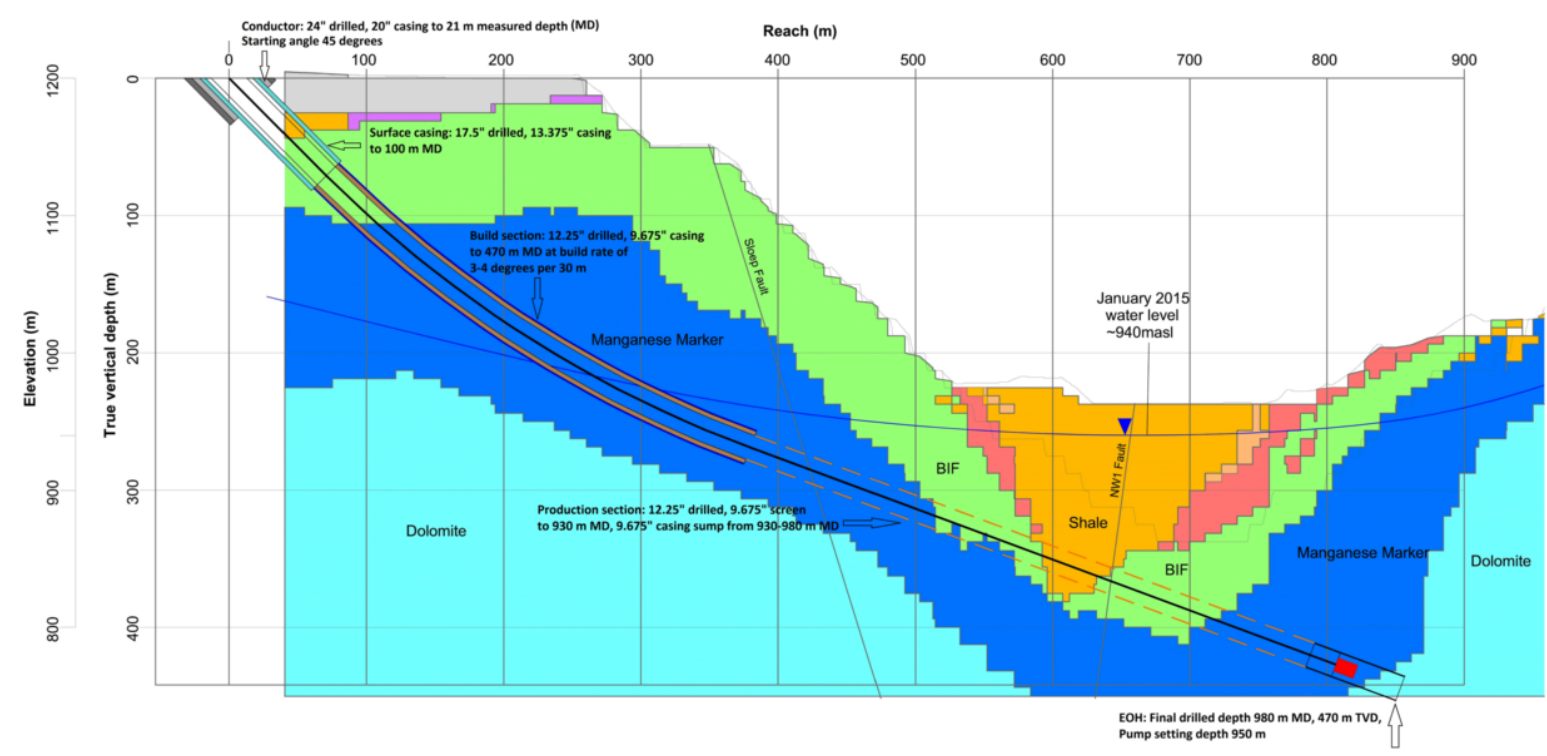

Figure 6-The final Plan 14 directional well trajectory and proposed construction

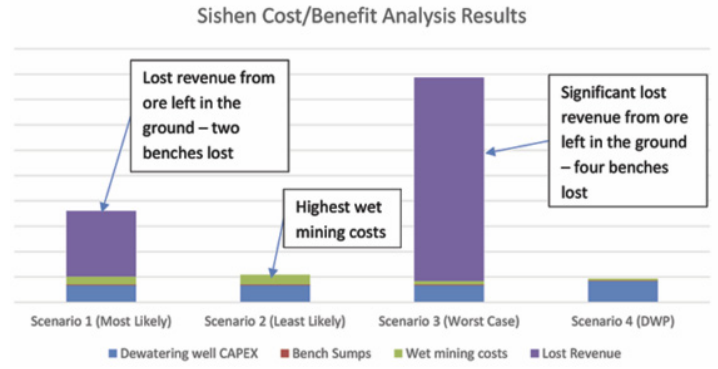

Figure 7-Chart showing the results of the cost-benefit analysis conducted for the Sishen GR35 DWP project TFS. The graph clearly shows that the costs associated with DWP are lower than all other scenarios, including the 'Least Likely', but especially relative to the 'Most Likely' and 'Worst Case' scenarios

Considering that the cost-benefit analysis was conducted using depressed iron ore prices in the same range as the current iron ore price, the trade-off analysis demonstrates the clear economic benefits of deploying DWPt for the GR35 pit at Sishen. However, the significant decline in iron ore prices and iron ore market fundamentals in 2014/15 resulted in a marked slowing of the rate of vertical advance in GR35 pit and significant changes to the mine plan. This enabled dewatering of the pit at a slower rate using the existing conventional dewatering system and resulted in DWPt being indefinitely delayed for the GR35 pit. However, since KIO remains committed to deploying the latest technologies at their Sishen and Kolomela operations in an effort to increase productivity and efficiency (Mining Review Africa, 2016), DWPt as a concept has been retained to address the potential dewatering requirements for other deep pits at Sishen and Kolomela should conditions warrant it.

\section{Conclusion}

As the mining industry is driven to exploiting ore resources that are deeper and in more inaccessible areas than ever before, systems previously thought to be robust solutions are increasingly being exposed as sub-optimal as mines get deeper and larger. The use of vertical dewatering wells is such an example, as the best hydrogeological targets cannot always be reached from the available drilling locations. Additionally, a drive to increase efficiency and productivity throughout the industry further pushes operations to reduce in-pit dewatering infrastructure and to improve the overall effectiveness of dewatering systems in the most cost-effective manner possible. As shown in this paper, the adaptation of mature directional drilling technologies has brought significant benefits to some of the largest open pit operations through the deployment of directional well placement technology. It is expected that as pits continue to get larger and deeper, and less in-pit space is available, the use of this technology will become more common as it is accepted as a cost-effective method for dewatering.

\section{References}

Astrup, J., Hammerbeck, E.C.I., and van den Berg, H. 1998. Iron. The Mineral Resources of South Africa. Wilson, M.G.C. and Annhaeusser, C.R. (eds.). Handbook 16. Council for Geoscience, Pretoria, South Africa. pp. 402-416.

DowLing, J. and Rhys-Evans, G. 2015. Oilfield directional well placement technology used for mine dewatering. Mining Magazine. May 2015. p. 28.

KUMBA IRON ORE. 2016a. Operations. http://www.angloamericankumba.com/ our-business/operations.aspx [Accessed 21 April 2016].

KUMBA IRON ORE. 2016b. Kumba Iron Ore Limited production and sales report for the quarter ended 31 March 2016.

http://www.angloamericankumba.com/media/press-releases/2016/21-042016.aspx [Accessed 21 April 2016].

MCCARTNEY, J. and ANDERSON, M. 2015. Mining innovation - why start from scratch. Mining Magazine. December 2015. p. 48.

Mining ReVIEW AfricA. 2016. Kumba says technology a company game-changer. http://www.miningreview.com/news/kumba-says-technology-a-companygame-changer/ [Accessed 11 May 2016].

NeL, E. and WhITE, T. 2015. Groundwater report, November 2015. Kumba Iron Ore Limited, Kathu, South Africa. 21 pp.

Schlumberger Water Services. 2015. Technical feasibility study for dewatering well placement technology at the GR35 Pit, Sishen Mine. Report no. 53810R2v11. Johannesburg, South Africa. 129 pp.

Schlumberger Water Services. 2014. Pre-feasibility assessment of the use of dewatering well placement technology at the GR35 Pit, Sishen Mine. Report no. 53810R1v1. Johannesburg, South Africa. 62 pp. 